\title{
Solvent-free and room temperature synthesis of 3-arylquinolines from different anilines and styrene oxide in the presence of $\mathrm{Al}_{2} \mathrm{O}_{3} / \mathrm{MeSO}_{3} \mathrm{H}$
}

\author{
Hashem Sharghi*, Mahdi Aberi, Mohsen Khataminejad and Pezhman Shiri
}

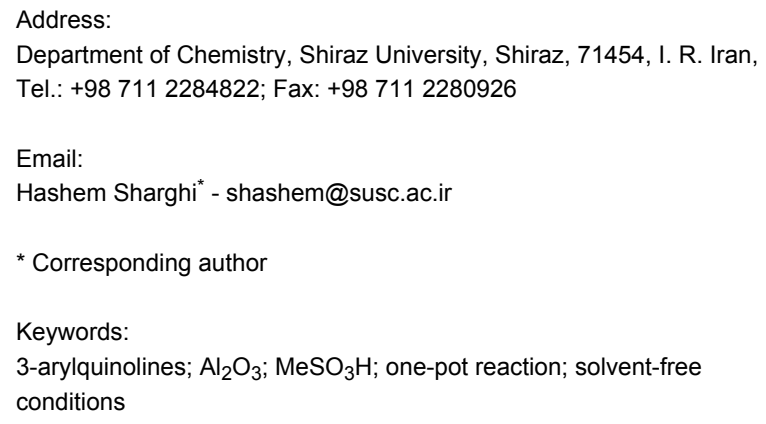

\author{
doi:10.3762/bjoc.13.193 \\ Received: 19 June 2017 \\ Accepted: 05 September 2017 \\ Published: 20 September 2017 \\ Associate Editor: L. Vaccaro
}

Beilstein J. Org. Chem. 2017, 13, 1977-1981.

() 2017 Sharghi et al.; licensee Beilstein-Institut.

License and terms: see end of document.

\begin{abstract}
A highly efficient, simple and environmentally friendly synthesis of 3-arylquinolines has been developed in the presence of $\mathrm{Al}_{2} \mathrm{O}_{3} /$ $\mathrm{MeSO}_{3} \mathrm{H}$ via one-pot reaction of anilines and styrene oxide. This methodology provides very rapid access to 3-arylquinolines in good to excellent yields under solvent-free conditions at room temperature in air.
\end{abstract}

\section{Introduction}

Quinoline derivatives have received considerable interest because they are found in numerous natural products with many biological activities. They have also played an important role in medicinal chemistry due to their pharmacological properties [1-4]. Transition metal-catalyzed processes [5-8] and metal-free paths [9-11] are two general approaches for the synthesis of this type of compounds. However, the existing methods suffer from complicated multistep processes, limited availability of substrates, toxic organic solvents, long reaction times, expensive catalyst and low regioselectivity in some cases.

One current area of modern synthetic organic chemistry is the development of powerful and effective practical procedures that minimize the requisite time, temperature, labour, and cost for the desired transformations $[12,13]$. The tandem reaction of anilines with styrene oxide via $\mathrm{C}-\mathrm{C}$ cleavage is the efficient synthetic route to quinolones [1]. The reaction was performed using $\mathrm{FeCl}_{3}$ as catalyst in 1,4-dioxane as solvent at $110{ }^{\circ} \mathrm{C}$ for $12 \mathrm{~h}$. According to the significance of this progress, we have decided to re-optimize it. The mixture of $\mathrm{Al}_{2} \mathrm{O}_{3}$ and $\mathrm{MeSO}_{3} \mathrm{H}$ has been previously used as an effective and mild reagent for organic transformations [14].

In continuation of our studies to develop new synthetic methods for heterocycles [15-19], herein, we disclose a novel route to the synthesis of 3-arylquinolines from aniline derivatives and styrene oxide at room temperature under solvent-free conditions (Scheme 1). 


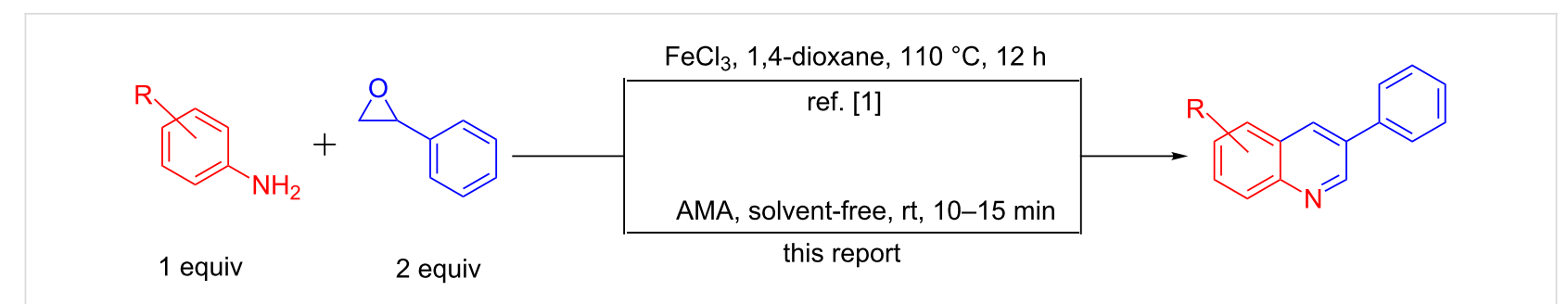

Scheme 1: Synthesis of 3-arylquinolines from anilines and styrene oxide. $A M A=\mathrm{Al}_{2} \mathrm{O}_{3} /$ methanesulfonic acid

Scheme 1 briefly compares the procedure reported by Wang and co-workers and our method. As it can be seen, the reaction can be performed under very short reaction time and low temperature.

\section{Results and Discussion}

To exploit optimized conditions for the synthesis of quinolines, the reaction of 3,4-dimethylaniline $(\mathbf{1}, 1.0 \mathrm{mmol})$ and styrene oxide $(2,2.0 \mathrm{mmol})$ in an open atmosphere was chosen as a model reaction (Table 1$)$.

Control experiments showed that in the absence of $\mathrm{Al}_{2} \mathrm{O}_{3}$ and $\mathrm{MeSO}_{3} \mathrm{H}$, no quinoline 3a was observed (Table 1, entry 1 ). The results also showed the importance of using both of $\mathrm{Al}_{2} \mathrm{O}_{3}$ and $\mathrm{MeSO}_{3} \mathrm{H}$. In the absence of $\mathrm{MeSO}_{3} \mathrm{H}$ no product was obtained (Table 1, entry 2). In the presence of $\mathrm{MeSO}_{3} \mathrm{H}, 6$,7-dimethyl-3phenylquinoline (3a) was obtained in $75 \%$ yield (Table 1 , entry 3). Finally, the best result was obtained using a mixture of
$\mathrm{Al}_{2} \mathrm{O}_{3}(0.1 \mathrm{~g})$ and $\mathrm{MeSO}_{3} \mathrm{H}(0.3 \mathrm{~mL})$ under solvent-free conditions at room temperature for $10 \mathrm{~min}$ (Table 1, entry 6). Various anilines with electron-withdrawing and electron-donating functional groups such as $o-\mathrm{Me}, m-\mathrm{Me}, p-\mathrm{Me}, m-\mathrm{Et}, p-\mathrm{MeO}, m-\mathrm{Br}$, $o$-Cl, 3,4-dimethyl and $p$-OEt were treated with styrene oxide to form the desired products (Table 2). In continuation of our study, aliphatic epoxides were also checked; unfortunately, they were not applicable for the preparation of quinolines. All novel and known compounds were characterized by their melting points, IR, ${ }^{1} \mathrm{H}$ NMR, ${ }^{13} \mathrm{C}$ NMR and mass spectra.

In order to recover $\mathrm{Al}_{2} \mathrm{O}_{3}$, the mixture was diluted with ethyl acetate and filtered. The solid on the filter paper was washed by ethyl acetate and evaporated. It should be noted that only $\mathrm{Al}_{2} \mathrm{O}_{3}$ was reused and it is necessary to add $\mathrm{MeSO}_{3} \mathrm{H}$ again for each cycle with recovered $\mathrm{Al}_{2} \mathrm{O}_{3}$. The recycled catalyst could be reused five times without any significant loss in activity (Figure 1).

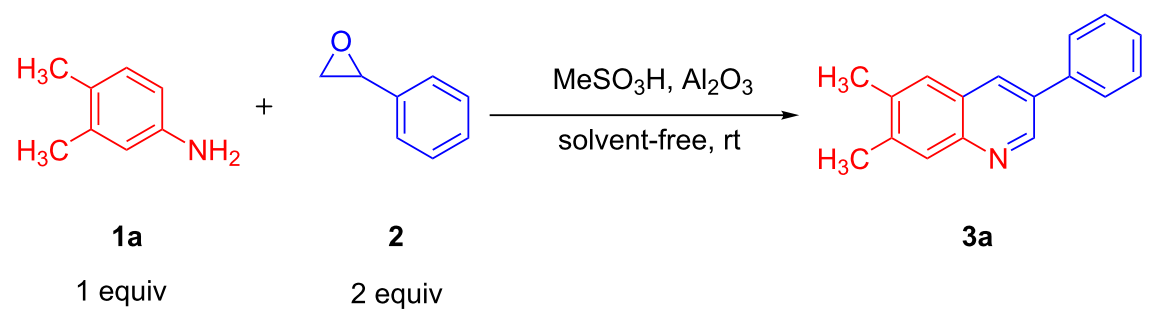

\begin{tabular}{lllll}
\hline Entry & Catalyst & Conditions & Time $(\mathrm{min})$ & ${\text { Yield }(\%)^{\mathrm{a}}}^{\mathrm{a}}$ \\
\hline 1 & None & solvent-free/rt & 60 & no reaction \\
2 & $\mathrm{Al}_{2} \mathrm{O}_{3}(0.1 \mathrm{~g})$ & solvent-free/rt & 60 & no reaction \\
3 & $\mathrm{MeSO}_{3} \mathrm{H}(0.3 \mathrm{~mL})$ & solvent-free/rt & 10 & 75 \\
4 & $\mathrm{Al}_{2} \mathrm{O}_{3}(0.1 \mathrm{~g})+\mathrm{MeSO}_{3} \mathrm{H}(0.1 \mathrm{~mL})$ & solvent-free/rt & 10 & 35 \\
5 & $\mathrm{Al}_{2} \mathrm{O}_{3}(0.1 \mathrm{~g})+\mathrm{MeSO}_{3} \mathrm{H}(0.2 \mathrm{~mL})$ & solvent-free/rt & 10 & 79 \\
6 & $\mathrm{Al}_{2} \mathrm{O}_{3}(0.1 \mathrm{~g})+\mathrm{MeSO}_{3} \mathrm{H}(0.3 \mathrm{~mL})$ & solvent-free/rt & 10 & 91 \\
7 & $\mathrm{Al}_{2} \mathrm{O}_{3}(0.2 \mathrm{~g})+\mathrm{MeSO}_{3} \mathrm{H}(0.3 \mathrm{~mL})$ & solvent-free/rt & 10 & 85 \\
\hline
\end{tabular}

alsolated yield. 
Table 2: One-pot synthesis of 3-arylquinolines from the reaction of different anilines $(1.0 \mathrm{mmol})$ with styrene oxide $(2.0 \mathrm{mmol})$ in the presence of $\mathrm{Al}_{2} \mathrm{O}_{3}$ and $\mathrm{MeSO}_{3} \mathrm{H}$ at room temperature under solvent-free conditions.

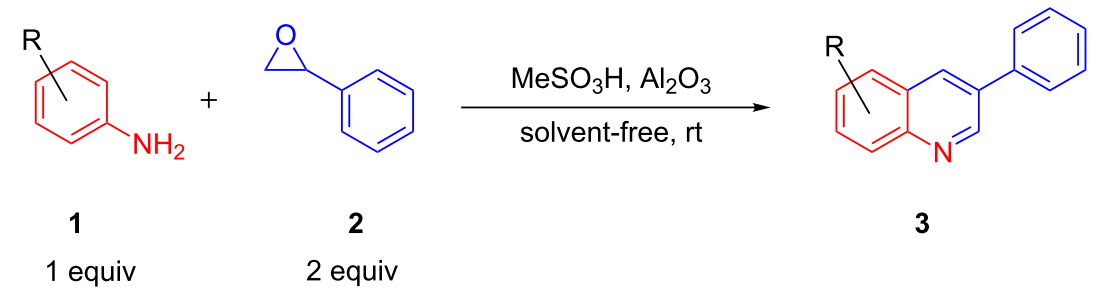

\begin{tabular}{|c|c|c|c|c|}
\hline Entry & Aniline & Product & Time (min) & Yield $(\%)^{a}$ \\
\hline 1 & $1 \mathrm{a}$ & $3 a$ & 10 & 91 \\
\hline 2 & 1b & $3 b$ & 12 & 89 \\
\hline 3 & 1c & $3 c$ & 12 & 88 \\
\hline 4 & $1 d$ & $3 d$ & 15 & 86 \\
\hline 5 & $1 \mathrm{e}$ & $3 e$ & 10 & 85 \\
\hline 6 & $1 f$ & $3 f$ & 15 & 84 \\
\hline 7 & $1 \mathrm{~g}$ & $3 g$ & 10 & 83 \\
\hline 8 & $1 \mathrm{~h}$ & $3 h$ & 10 & 82 \\
\hline
\end{tabular}


Table 2: One-pot synthesis of 3-arylquinolines from the reaction of different anilines $(1.0 \mathrm{mmol})$ with styrene oxide $(2.0 \mathrm{mmol})$ in the presence of $\mathrm{Al}_{2} \mathrm{O}_{3}$ and $\mathrm{MeSO}_{3} \mathrm{H}$ at room temperature under solvent-free conditions. (continued)

9<smiles>Nc1ccccc1</smiles>

$1 \mathrm{i}$

10<smiles>CCOc1ccc(N)cc1</smiles>

1j<smiles>Cc1ccccc1N</smiles>

$1 \mathrm{k}$

12

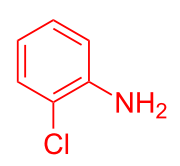

11<smiles>C1=N[Al]c2ccccc2C=C1c1ccccc1</smiles>

3j<smiles>Cc1cccc2cc(-c3ccccc3)cnc12</smiles>

3k<smiles>Clc1cccc2cc(-c3ccccc3)cnc12</smiles>

10

3I

aIsolated yield.

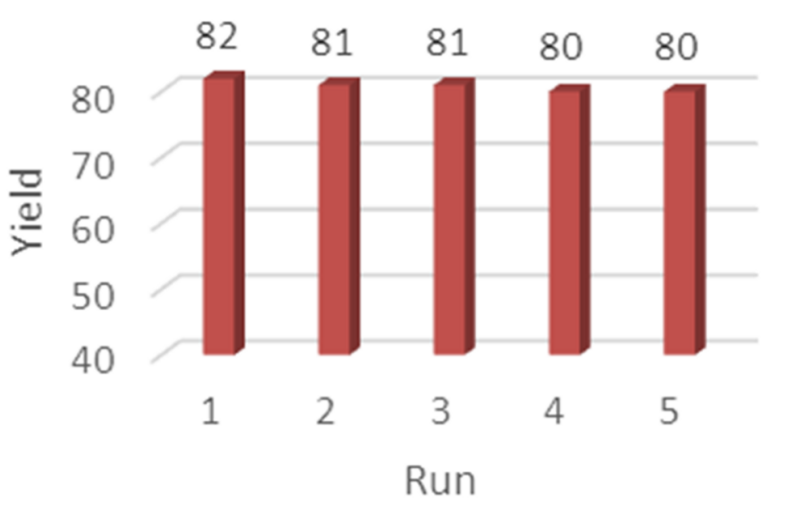

Figure 1: Investigation of the reusability of $\mathrm{Al}_{2} \mathrm{O}_{3}$.

\section{Conclusion}

In conclusion, $\mathrm{Al}_{2} \mathrm{O}_{3}$ and $\mathrm{MeSO}_{3} \mathrm{H}$ exhibited an excellent reactivity in the one-pot synthesis of 3-arylquinolines using anilines and styrene oxide. The methodology has the advantages of good to excellent yields, readily available starting materials, short reaction time, mild and solvent-free conditions. The method utilizes nonexpensive reagents and starting materials, as well. Further work is in progress to extend the scope and to investigate mechanism aspects of this reaction.

\section{Experimental} Instrumentation, analysis and starting material

Starting materials and solvents were purchased from Aldrich, Fluka, and Merck. IR spectra were obtained using a Shimadzu Fourier transform infrared (FTIR) 8300 spectrophotometer. Melting points were determined in open capillary tubes in a Büchi-535 circulating oil melting point apparatus. Mass spectra were determined on a Shimadzu GCMS-QP 1000 EX instrument at 70 or $20 \mathrm{eV}$. NMR spectra were recorded on a Bruker Avance DPX-250 $\left({ }^{1} \mathrm{H}\right.$ NMR $250 \mathrm{MHz}$ and ${ }^{13} \mathrm{C}$ NMR $62.9 \mathrm{MHz}$ ) spectrometer in pure deuterated solvents with tetramethylsilane (TMS) as an internal standard. The used methanesulfonic acid $98 \%$ and acidic alumina $\left(\mathrm{Al}_{2} \mathrm{O}_{3}\right)$ type $540 \mathrm{C}$ were purchased from Fluka. The elemental analyses were performed with a Thermo Finnigan CHNS-O analyzer, 1112 series. The purity determination of the substrates and reaction monitoring were accomplished by TLC on silica gel PolyGram SILG/UV 254 plates. Column chromatography was carried out on short columns of silica gel 60 (70-230 mesh) in glass columns.

\section{General procedure for the synthesis of quino-} lines in the presence of $\mathrm{Al}_{2} \mathrm{O}_{3} / \mathrm{MeSO}_{3} \mathrm{H}$

Aniline $(1.0 \mathrm{mmol})$ and styrene oxide $(2.0 \mathrm{mmol})$ were added to a mixture of $\mathrm{MeSO}_{3} \mathrm{H}(0.3 \mathrm{~mL})$ and $\mathrm{Al}_{2} \mathrm{O}_{3}(0.1 \mathrm{~g})$. The mixture 
was stirred at room temperature in solvent-free conditions for the period of time reported in Table 2. After completion of the reaction, the mixture was diluted with ethyl acetate, and filtered. The filtrate was washed with a solution of $\mathrm{NaHCO}_{3}(5 \%$; $3 \times 30 \mathrm{~mL}$ ) and then $30 \mathrm{~mL}$ deionized water. The solution was dried over magnesium sulfate; the solvent was evaporated to give the crude product, which was purified by silica gel column chromatography employing $n$-hexane/ethyl acetate (10:1) as eluent.

\section{Supporting Information}

\section{Supporting Information File 1}

Additional experimental and analytical data and NMR spectra.

[http://www.beilstein-journals.org/bjoc/content/

supplementary/1860-5397-13-193-S1.pdf]

\section{Acknowledgements}

We gratefully acknowledge the financial support of this work by the Shiraz University Research Council and the Iran National Elite Foundation. We are also grateful to Mr. H. Sajedian Fard and Mr. M. S. Darvish Tafvizi for their helpful cooperation.

\section{References}

1. Zhang, Y.; Wang, M.; Li, P.; Wang, L. Org. Lett. 2012, 14, 2206-2209. doi:10.1021/ol300391t

2. Michael, J. P. Nat. Prod. Rep. 2001, 18, 543-559. doi:10.1039/B005387M

3. Funayama, S.; Murata, K.; Noshita, T. Heterocycles 2001, 54, 1139-1148. doi:10.3987/REV-00-SR(I)8

4. Sawada, Y.; Kayakiri, H.; Abe, Y.; Imai, K.; Mizutani, T.; Inamura, N.; Asano, M.; Aramori, I.; Hatori, C.; Katayama, A. J. Med. Chem. 2004, 47, 1617-1630. doi:10.1021/jm030159x

5. Zhang, Z.; Tan, J.; Wang, Z. Org. Lett. 2008, 10, 173-175. doi:10.1021/ol702153x

6. Liu, X.-Y.; Ding, P.; Huang, J.-S.; Che, C.-M. Org. Lett. 2007, 9, 2645-2648. doi:10.1021/ol070814I

7. Gabriele, B.; Mancuso, R.; Salerno, G.; Ruffolo, G.; Plastina, P. J. Org. Chem. 2007, 72, 6873-6877. doi:10.1021/jo071094z

8. Gaddam, V.; Ramesh, S.; Nagarajan, R. Tetrahedron 2010, 66, 4218-4222. doi:10.1016/j.tet.2010.03.095

9. Zhao, Y.-L.; Zhang, W.; Wang, S.; Liu, Q. J. Org. Chem. 2007, 72, 4985-4988. doi:10.1021/jo070069q

10. Tanaka, S.-y.; Yasuda, M.; Baba, A. J. Org. Chem. 2006, 71, 800-803. doi:10.1021/jo052004y

11. Hessian, K. O.; Flynn, B. L. Org. Lett. 2006, 8, 243-246. doi:10.1021/ol052518j

12. Zhang, Y.; Li, P.; Wang, L. J. Heterocycl. Chem. 2011, 48, 153-157. doi:10.1002/jhet.417

13. Trost, B. M. Acc. Chem. Res. 2002, 35, 695-705. doi:10.1021/ar010068z
14. Sharghi, H.; Beni, A. R. S. Synthesis 2004, 2900-2904. doi:10.1055/s-2004-831253

15. Sharghi, H.; Aberi, M.; Shiri, P. Appl. Organomet. Chem. 2017, in press. doi:10.1002/aoc.3761

16. Sharghi, H.; Shiri, P. Synthesis 2015, 47, 1131-1146. doi:10.1055/s-0034-1379951

17. Sharghi, H.; Shiri, P.; Aberi, M. Mol. Diversity 2014, 18, 559-575. doi:10.1007/s11030-014-9527-5

18. Sharghi, H.; Shiri, P.; Aberi, M. Synthesis 2014, 46, 2489-2498. doi:10.1055/s-0034-1378206

19. Sharghi, H.; Aberi, M.; Doroodmand, M. M.; Shiri, P. J. Iran. Chem. Soc. 2017, 14, 1557-1573. doi:10.1007/s13738-017-1097-x

\section{License and Terms}

This is an Open Access article under the terms of the Creative Commons Attribution License

(http://creativecommons.org/licenses/by/4.0), which permits unrestricted use, distribution, and reproduction in any medium, provided the original work is properly cited.

The license is subject to the Beilstein Journal of Organic Chemistry terms and conditions:

(http://www.beilstein-journals.org/bjoc)

The definitive version of this article is the electronic one which can be found at: doi:10.3762/bjoc. 13.193 